\title{
Design and analysis of an optimized microfluidic channel for isolation of circulating tumor cells using deterministic lateral displacement technique
}

\author{
Rituraj Bhattacharjee $^{1} \cdot$ R. Kumar ${ }^{1} \cdot$ Fenil Chetankumar Panwala $^{1} \cdot$ P. Mohamed Shakeel ${ }^{2}$
}

Received: 8 April 2020 / Accepted: 30 May 2020 / Published online: 21 June 2020

(C) The Author(s) 2020

\begin{abstract}
Circulating tumor cells (CTCs) are extremely scarce cells which cut off from a primary tumor and percolate into the circulation of blood flow and are, thus, critical for precise cancer detection and treatment. Deterministic lateral displacement (DLD) which exploits asymmetric splitting of laminar flow around the implanted microposts has displayed trustworthy capabilities in separating cells of varying sizes. In this research work, a microfluidic channel consisting of three symmetrically aligned inlets and outlets and embedded circular posts has been proposed which effectively separates the CTCs from lymphocytes utilizing the concept of DLD. Using a commercial software COMSOL Multiphysics 5.4, the design of the proposed microchannel has been simulated and analyzed considering an injected blood sample containing massive CTCs and slim WBCs of radii $13.5 \mu \mathrm{m}$ and $6 \mu \mathrm{m}$, respectively. The proposed model of microchannel isolates the CTCs from WBCs at a comparatively higher sample mass flow rate of $4 \times 10^{-6} \mathrm{~kg} / \mathrm{s}$ and Reynolds number of 8.9 thereby operating efficiently at higher throughput, and offers excellent linearity in terms of velocity magnitude, pressure, shear rate and Reynolds number. The computational analysis of the proposed microchannel reveals that it can isolate CTCs from WBCs with better separation ratio, offers higher throughput, reduces possibilities of clogging and maintains better uniformity of pressure distribution and other flow parameters when compared with existing microchannel designs. The maximum separation ratio for CTCs and WBCs has been obtained as $84 \%$ and $96 \%$, respectively.
\end{abstract}

Keywords Circulating tumor cells $\cdot$ Deterministic lateral displacement $\cdot$ Microfluidics $\cdot$ COMSOL multiphysics $\cdot$ Bioparticles

\section{Introduction}

The recent advancements in MEMS (microelectromechanical system) originating from silicon integrated circuit technology have drastically brought significant developments showcasing many technical breakthroughs, especially in the field of biotechnology. Over the recent years, an expeditious development of technology has been noticed in various domains of medical science out of which bio-particle

R. Kumar

rajagopal.kumar4@gmail.com

1 Department of Electronics and Instrumentation Engineering, National Institute of Technology Nagaland, Dimapur, Nagaland 797103, India

2 Faculty of Information and Communication Technology, Universiti Teknikal Malaysia Melaka (UTeM), Melaka, Malaysia separation has captured prime attention as the research focus has shifted towards advancement in therapeutic methods for prevention of viral diseases. Many conventional analyses in biomedical industry mainly depend on the techniques and the operator's experiences with the existing traditional instruments in macroscale which offer very less accuracy in detection with adulterated samples and additionally require consumption of samples at a higher rate. Since the last decade, biomedical analysis of a microfluidic biological system has remained an emerging research area which continues to grow further every year with the introduction of new developments in sample analysis methods. Advances in miniaturization of apparatus such as micro total analysis systems ( $\mu$-TAS) or popularly called 'Lab-on-a-chip' has reduced complexity at macro-level by integrating specific miniaturized systems like micromixers, microvalves, microchannels and micropumps. The corresponding microfluidic devices for biological analysis demand less reagent consumption, 
lower sample utilization and low cost when compared with several conventional methods adopted [1-8].

In the constantly evolving field of BioMEMS, sorting of bio-particles has received special interest in diagnostics and therapeutic applications like conducting bioassays of living cells or tissues and purification of target cells for analysis. For accomplishing separation of bio-particles, some of the main parameters of cells considered are mass, shape, size, compressibility, deformability, density and other physical features. Figure 1 displays the different techniques available till date that are commonly used for sorting of cells.

Among the passive methods, pinched flow fractionation (PFF) is a technique of separating cells involving a narrow channel called pinched segment where the cells align along the channel side wall and get separated through different outlets based on critical diameter [9]. Another effective method of separation is deterministic lateral displacement (DLD) where particles drive through the arrays in post to post positions. One of the fundamental and influential physical principles in microfluidics is hydrodynamic force including dean rotation force and inertial force, which are employed as per the fluid dynamic theory in microchannel network and used explicitly to create a hydrodynamic force separation system. Additionally, filtration is one of the most commonly used techniques in hydrodynamics to analyze the bio-particles suspended with fluid flow due to sedimentation. Among the active techniques, Acoustic method makes use of the ultrasonic standing waves causing manipulation of cells compared to other methods of separation like magnetic, dielectrophoretic and others. The fundamental principle of acoustic sorting is based on using ultrasonic standing waves at an instant generating pressure gradients for sorting. Dielectrophoresis (DEP) is based on the behavior of polarizable cells or particles when placed in an electric field effect with non-uniformity and particle motion produced by DEP force is regulated by the existing electric field and the properties of electric particles or solutions. Magnetic separation can be materialized using magnetophoresis technique where target cells are bonded to the magnetic beads and sorting takes place based on the deflection of cells based on magnetic susceptibility, size and flow rate.

In the current medical scenario where cancer patients are on the rise, a lot of researchers have been focused at isolation of CTCs from blood as a fluid biopsy for early diagnosis of cancer. As a matter of fact, CTCs are very scarce, counting around few among $10^{9}$ of cells in every $\mathrm{ml}$ of blood in patients with metastatic cancer [10]. The exact role of CTCs during metastasis process remains unclear. Therefore, to expedite cancer diagnosis, treatment and the study of tumor metastasis, efficient and reliable methods for CTCs enumeration, characterization and separation are in high demand [11]. The diameter of CTCs usually lies in the range of 12-20 $\mu \mathrm{m}$ [12-14] but practically in certain literatures [15] these have been reported to have $27 \mu \mathrm{m}$ diameter.

To separate CTCs, most relevant and commonly used methods are based on label-less isolation of CTCs, including microfluidic filters [16, 17], inertial focusing [18], deterministic lateral displacement (DLD) [19], acoustics [20] and dielectrophoresis (DEP) [21]. These methods operate based on the fact that CTCs are larger and stiffer than regular blood cells. However, these methods also have their limitations. Acoustics and dielectrophoresis (DEP) require extra force fields and longer process time whereas microfluidic filters and inertial focusing have clogging issues.

DLD is a prominent method among popularly used techniques for cell separation in the recent years. It is basically a size-based separation technique that exploits the asymmetric splitting of laminar flow around the implanted microposts which are placed in slanted array in the interior of the microfluidic channel. This array of microposts induces an effective

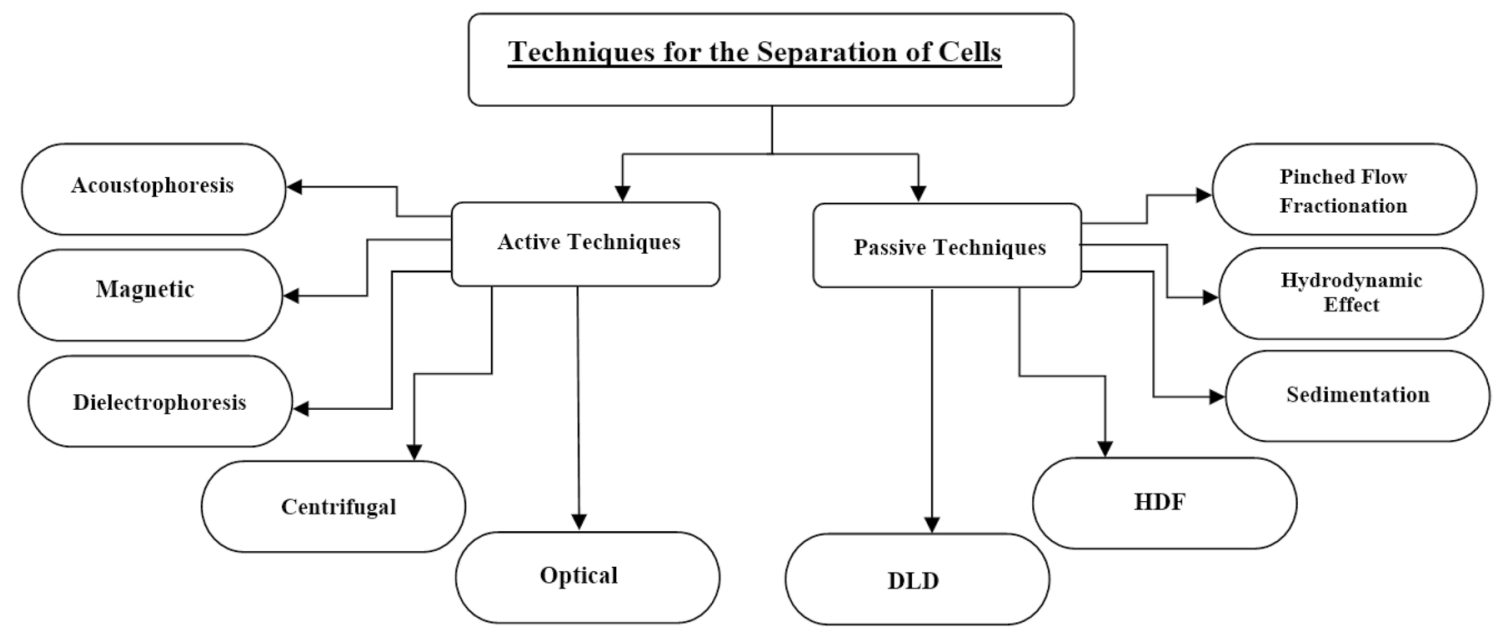

Fig. 1 Classification chart showing techniques for the separation of cells 
displacement due to the hydrodynamic forces that act under laminar fluid passage pattern. Estimation of the suspended particle's displacement in a microfluidic channel during its passage through the array of microposts is done based on a parameter called critical diameter $\left(D_{\mathrm{c}}\right)$. If the diameter of the suspended particle $\left(D_{\mathrm{p}}\right)$ is less than the critical diameter, there will be no lateral shifting of streamline leading to an irregular pattern of flow. On the contrary, as shown in Fig. 2, if the particle size exceeds the critical diameter, the particle flow trajectory will follow a laterally shifted flow pattern. In DLD devices, the row shift fraction $(\varepsilon)$ is a geometrical parameter which is the ratio of shifted distance between microposts and distance from center-to-center of adjacent microposts. For representation of lateral row shifting of microposts in DLD array, a parameter called tilted angle $(\theta)$ is used signifying the slope of micropost arrays. A period number $(N)$ is also considered which signifies that the microposts of row $N+1$ are in the same lateral position as the first row.

These parameters are related by Eq. (1) which directly links the parameter $\varepsilon$ with $N$ and $\theta$ [22]:

$\varepsilon=\frac{1}{N}=\tan (\theta)$.

The critical diameter $\left(D_{c}\right)$ of a DLD device can be estimated for lower Reynolds number (Re) with the help of Eq. (2) which is valid for operation involving lower throughput $(\operatorname{Re} \leq 1)[23]$.

$D_{c}=1 \cdot 4 \cdot g \cdot \varepsilon^{0.48}$

In cases of moderate throughput operation $(1<\operatorname{Re}<10)$, recently a modified formula has been proposed as stated in Eq. (3) to calculate the critical diameter $\left(D_{c}\right)$ [24].

$D_{c}=1 \cdot 2 \cdot g \cdot \varepsilon^{0.48} e^{-0.01 R e}$.

Among the trending implementations of a DLD device to separate the CTCs, the design proposed by Zhou et al. is the latest one [25]. The design consists of two sample inlets and one central buffer inlet which causes an effective CTC separation while maintaining the flow rate of sample as $150 \mu \mathrm{L} / \mathrm{min}$. The device was shown to perform well at lower flow rate, but offered less purity at higher sample flow rate. Investigations have been done to cause an effective and efficient separation process of CTCs at higher throughput, i.e., at higher sample flow rate [24]. In this proposed work, design of an optimized microchannel has been presented which incorporates the concept of DLD to conduct the isolation of CTCs at a comparatively higher sample flow rate. The linearity of certain important parameters like pressure, velocity magnitude, shear rate and Reynolds number have been checked at the outlet side and found optimum for generating better separation efficiency.

\section{Proposed microchannel design}

\section{Layout of the proposed model of microchannel}

The proposed microchannel structure, as represented in Fig. 3, consists of three symmetrically aligned inlets, namely two buffer inlets and one sample inlet. The length and width of the considered microchannel are $300 \mu \mathrm{m}$ and $200 \mu \mathrm{m}$, respectively. Three outlets are provided out of which the topmost corresponds to CTC outlet and the central one serves as an outlet for separated WBCs. The middle section of the microchannel houses an array of circular microposts arranged as per the principle of DLD. The lower outlet has been provided for uniform fluid pressure distribution after the DLD array which would help to reduce clogging issues reported in earlier designs.

\section{Geometrical arrangement of the circular microposts forming DLD array}

Figure 4 showcases the different dimensions involved in selecting the design parameters for building the DLD array.

Fig. 2 Representation of flow patterns of particles having diameters less than $D_{c}$ and more than $D_{\mathrm{c}}$ when allowed to flow through DLD array of microposts

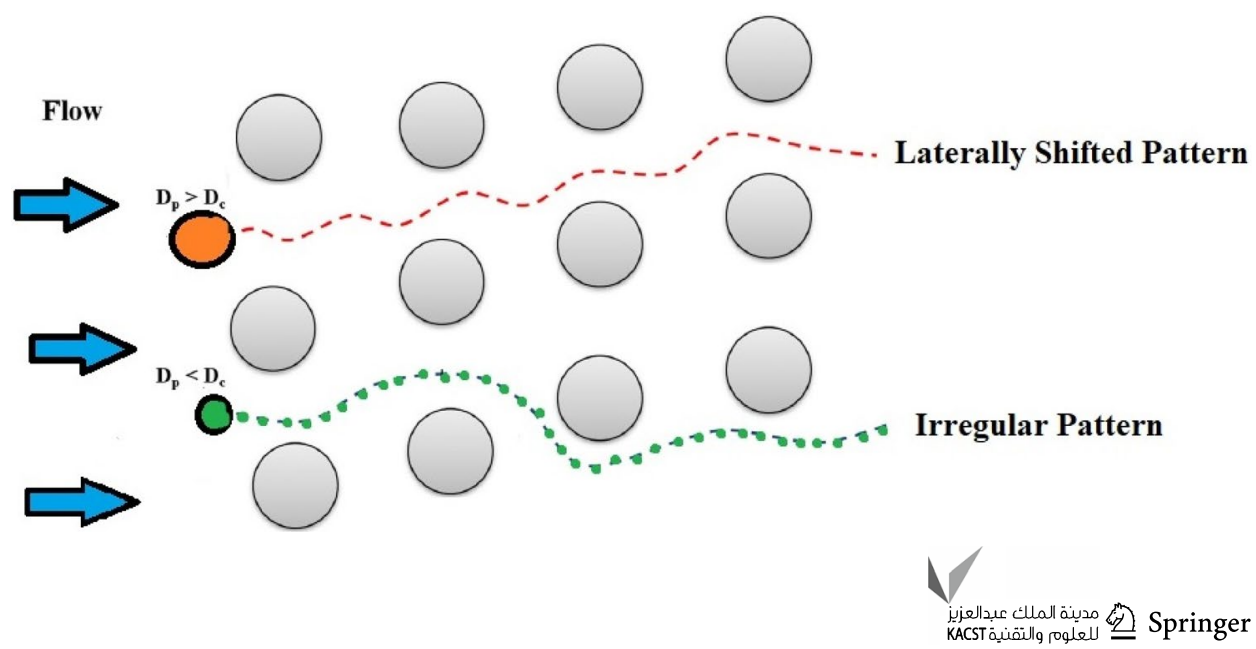


Fig. 3 Layout of the proposed microchannel

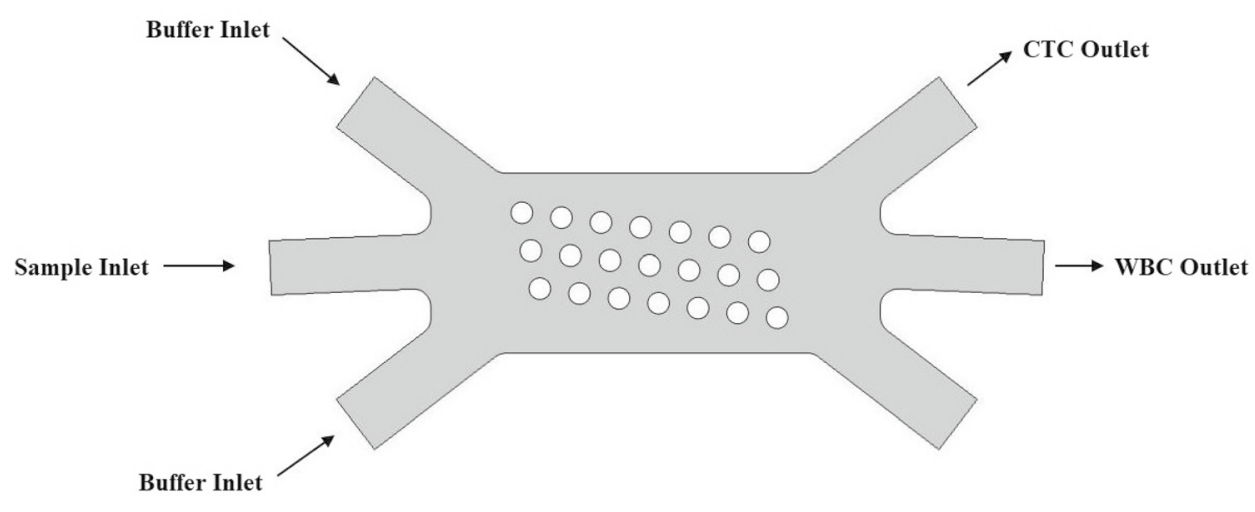

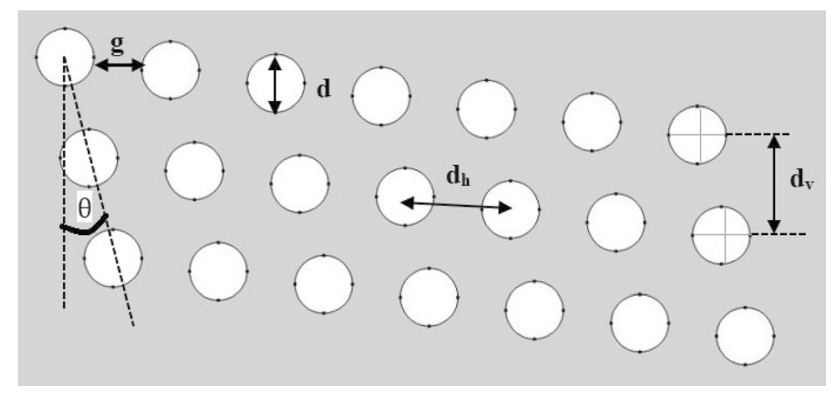

Fig. 4 Different design parameters for DLD array

Table 1 Values of different design parameters

\begin{tabular}{lll}
\hline $\begin{array}{l}\text { Parameter Repre- } \\
\text { sentation }\end{array}$ & Parameter Meaning & Value \\
\hline $\mathrm{g}$ & Gap between microposts & $22 \mu \mathrm{m}$ \\
$\mathrm{d}$ & Diameter of microposts & $12 \mu \mathrm{m}$ \\
$\theta$ & Tilted angle & $13.38^{0}$ \\
$\mathrm{~d}_{\mathrm{h}}$ & Horizontal center-to-center distance & $34 \mu \mathrm{m}$ \\
$\mathrm{d}_{\mathrm{v}}$ & Vertical center-to-center distance & $21 \mu \mathrm{m}$ \\
\hline
\end{tabular}

Table 1 represents the different values of the highlighted parameters chosen for simulating the geometry of the microchannel.

\section{Theoretical analysis for calculation of critical diameter $\left(D_{c}\right)$}

For low throughput operation, as per Eq. (2), the critical diameter can be calculated as:

$D_{c}=1.4 \cdot g \cdot \varepsilon^{0.48}$.

As per the dimensions considered in the proposed DLD $\varepsilon=\tan (\theta)=\frac{5 \mu \mathrm{m}}{21 \mu \mathrm{m}}=0.238$.

Accordingly, considering $g=22 \mu \mathrm{m}$, critical diameter can be obtained as:

$D_{\text {c }}=1.4 \times 22 \times 10^{-6} \times(0.238)^{0.48}=15.4634 \mu \mathrm{m}$.

For higher throughput operation, as per Eq. (3), the critical diameter can be found as:

$D_{\mathrm{c}}=1.2 \cdot g \cdot \varepsilon^{0.48} \mathrm{e}^{-0.01 \mathrm{Re}}$.

For testing the simulated model, Reynolds number $(\mathrm{Re})$ was chosen as 8.9 at the inlet side corresponding to the sample mass flow rate of $4 \times 10^{-6} \mathrm{~kg} / \mathrm{s}$.

Therefore, considering $g=22 \mu \mathrm{m}$ and $\varepsilon=0.238$, critical diameter for higher throughput operation can be obtained as:

$D_{\text {c }}=1.2 \times 22 \times 10^{-6} \times(0.238)^{0.48} \mathrm{e}^{-0.01 \times 8.9}=12.125 \mu \mathrm{m}$.

It can, thus, be stated that for both low throughput and high-throughput operations, the critical diameter obtained falls in the range of 12.1-15.4 $\mu \mathrm{m}$ which satisfies the requirement for separation of massive CTCs (radius $13.5 \mu \mathrm{m}$ ) from slim WBCs (radius $6 \mu \mathrm{m}$ ).

\section{Result and discussion}

In this section, simulation responses as obtained after computational analysis of the microchannel in COMSOL Multiphysics 5.4 software have been presented followed by plots representing variation of different fluid parameters with changes in flow rates. The different essential cell parameters considered for particle tracing with mass in simulated microchannel model are presented in Table 2 which have been referred from standard research articles on circulating tumor cells $[15,26]$. array, 
Table 2 Different cell parameters considered for particle tracing in microchannel

\begin{tabular}{lll}
\hline Cell type & Mass $(\mathrm{pg})$ & Diameter $(\mu \mathrm{m})$ \\
\hline $\begin{array}{l}\text { CTC (extracted from an ovarian } \\
\text { cancer patient) }\end{array}$ & 36.8 & 27 \\
WBC & 19.3 & 12 \\
\hline
\end{tabular}

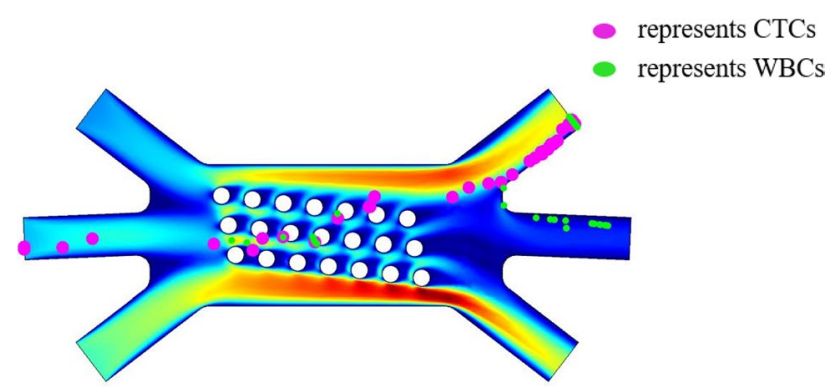

Fig. 5 Simulation response with water as conducting medium showing separation of CTCs at sample velocity flow rate of $4.75 \mathrm{~m} / \mathrm{s}$

\section{Simulation response of the proposed microchannel model with water as the conducting medium considering velocity flow rate}

Using the particle tracing feature of COMSOL Multiphysics 5.4, the microchannel was tested by injecting a blood sample containing WBCs and CTCs of radii $6 \mu \mathrm{m}$ and $13.5 \mu \mathrm{m}$, respectively, at sample inlet with water as the conducting fluid. Figure 5 shows the simulation response of the proposed model which clearly shows an efficient separation of CTCs at the sample velocity flow rate of $4.75 \mathrm{~m} / \mathrm{s}$. The velocity flow rates of upper buffer inlet and lower buffer inlet were maintained at $4 \mathrm{~m} / \mathrm{s}$ and $6.7 \mathrm{~m} / \mathrm{s}$, respectively.

\section{Simulation response of the proposed microchannel model with blood as the conducting medium considering velocity flow rate}

Using the particle tracing feature of COMSOL Multiphysics 5.4, the microchannel was tested by injecting a blood sample containing WBCs and CTCs of radii $6 \mu \mathrm{m}$ and $13.5 \mu \mathrm{m}$, respectively, at sample inlet with blood as the conducting fluid. Figure 6 shows the simulation response of the proposed model which clearly shows an efficient separation of CTCs at the sample velocity flow rate of $12.3 \mathrm{~m} / \mathrm{s}$. The velocity flow rates of upper buffer inlet and lower buffer inlet were maintained at $4 \mathrm{~m} / \mathrm{s}$ and $6.7 \mathrm{~m} / \mathrm{s}$, respectively.

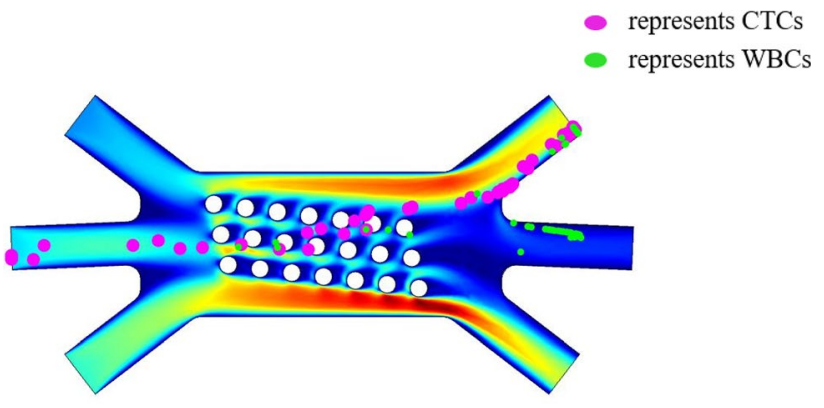

Fig. 6 Simulation response with blood as conducting medium showing separation of CTCs at sample velocity flow rate of $12.3 \mathrm{~m} / \mathrm{s}$

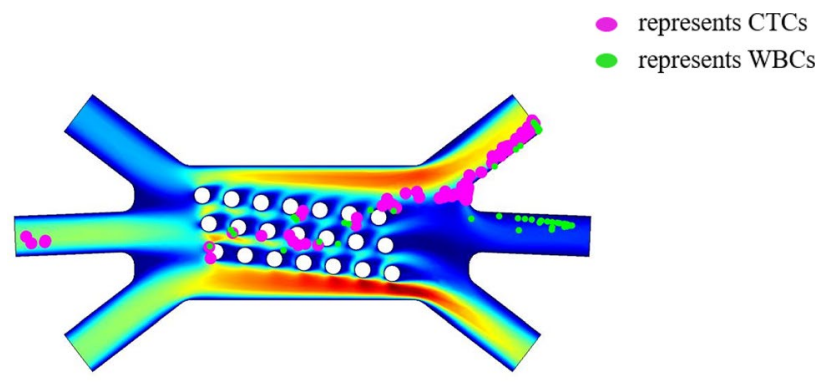

Fig. 7 Simulation response with blood as conducting medium at much higher sample mass flow rate of $4 \times 10^{-6} \mathrm{~kg} / \mathrm{s}$ and $\mathrm{Re}=8.9$

\section{Simulation response of the proposed microchannel model with blood as the conducting medium considering mass flow rate}

Using the particle tracing feature of COMSOL Multiphysics 5.4, the microchannel was tested by injecting a blood sample containing WBCs and CTCs of radii $6 \mu \mathrm{m}$ and $13.5 \mu \mathrm{m}$, respectively, at sample inlet with blood as the conducting fluid considering a higher sample mass flow rate to check for higher throughput operation. The channel thickness of all the three inlets were reduced to $0.01 \mathrm{~mm}$ to generate higher Re flow regime. In Fig. 7, simulation response of the proposed model clearly shows an efficient separation of CTCs at a comparatively higher sample mass flow rate of $4.3 \times 10^{-6} \mathrm{~kg} / \mathrm{s}$. The mass flow rates of upper buffer inlet and lower buffer inlet were maintained at $30.8 \times 10^{-7} \mathrm{~kg} / \mathrm{s}$ and $5.96 \times 10^{-6} \mathrm{~kg} / \mathrm{s}$, respectively. The device model cited in [16] showed separation of CTCs with reasonable purity at $150 \mu \mathrm{l} / \mathrm{min}$ which is equivalent to $2.65 \times 10^{-6} \mathrm{~kg} / \mathrm{s}$ considering density of blood as $1060 \mathrm{~kg} /$ $\mathrm{m}^{3}$. Thus, the simulation response clearly validates the efficient operation of the microchannel at much higher mass flow rate and Reynolds number (taken as 8.9).

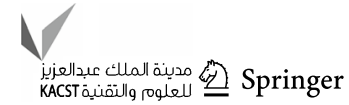




\section{Plot of variation of important flow parameters with changes in sample velocity flow rate}

Figure 8a-d depicts the variation of flow parameters, namely pressure, Reynolds number, shear rate and velocity magnitude at different outlets of the proposed microchannel with changes in velocity flow rate using water as the conducting fluid. The CTCs get effectively separated at the sample velocity flow rate of $4.75 \mathrm{~m} / \mathrm{s}$ and linearity of the flow parameters is maintained as we vary the flow rate further from that separation point. Similarly, Fig. 9a-d depicts the variation of flow parameters, namely pressure, velocity magnitude, shear rate and Reynolds number at different outlets of the proposed microchannel with changes in velocity flow rate using blood as the conducting fluid. The CTCs get effectively separated at the sample velocity flow rate of $12.3 \mathrm{~m} / \mathrm{s}$ and linearity of the flow parameters
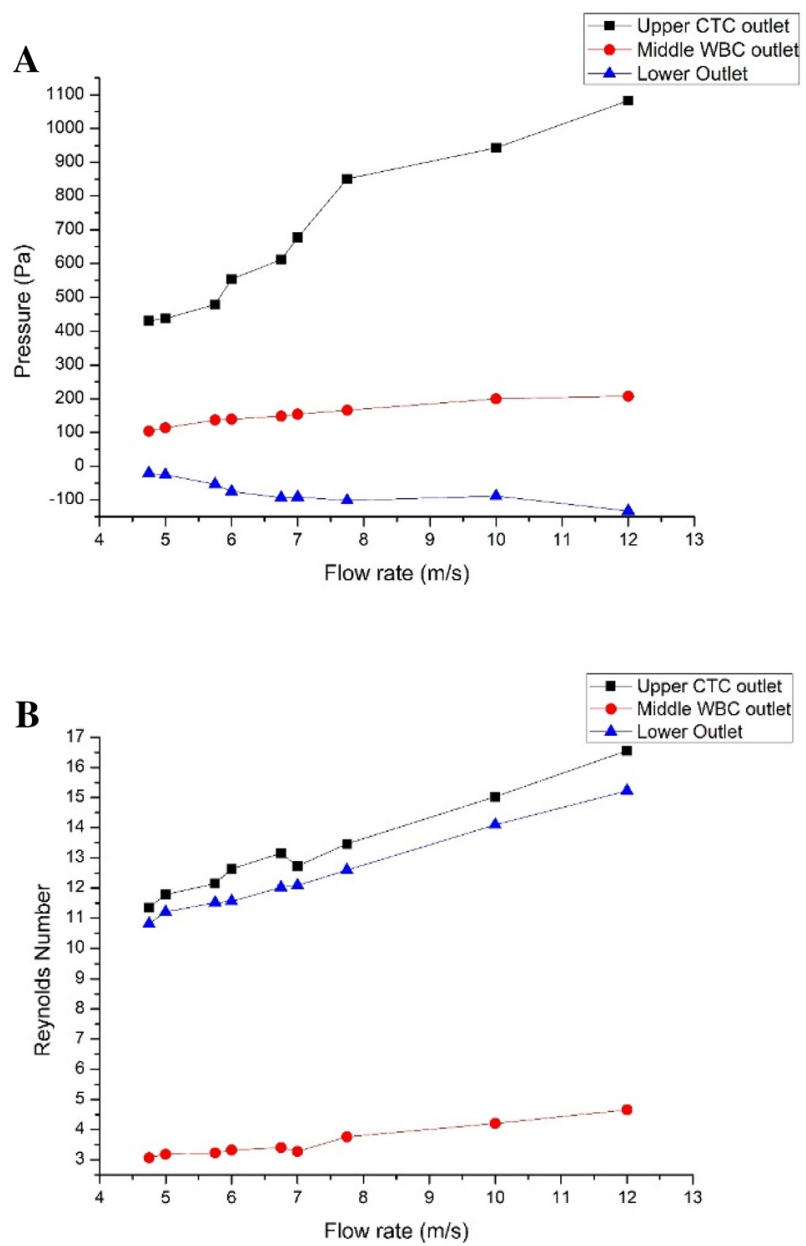

Figure 8 a Plot of variation of pressure $(\mathrm{Pa})$ at different outlets with changes in sample flow rate $(\mathrm{m} / \mathrm{s})$ when water was used as conducting fluid. b Plot of variation of Reynolds number at different outlets with changes in sample flow rate $(\mathrm{m} / \mathrm{s})$ when water was used as conducting fluid. c Plot of variation of shear rate $(1 / \mathrm{s})$ at different outlets with is maintained as we vary the flow rate further from that separation point.

\subsubsection{Plot of variation of flow parameters with changes in sample velocity flow rate with water as the conducting fluid}

Figure 8a showcases the variation of pressure $(\mathrm{Pa})$ at the three outlets with the changes in sample flow rate $(\mathrm{m} / \mathrm{s})$. The plot clearly highlights the uniformity in pressure distribution at different outlets after the separation point of CTCs, i.e., at $4.5 \mathrm{~m} / \mathrm{s}$ with water as the conducting fluid.

Figure $8 \mathrm{~b}$ showcases the variation of Reynolds number at the three outlets with the changes in sample flow rate $(\mathrm{m} / \mathrm{s})$. The plot clearly highlights the uniformity in Reynolds number at different outlets after the separation point of CTCs, i.e., at $4.5 \mathrm{~m} / \mathrm{s}$ with water as the conducting fluid.
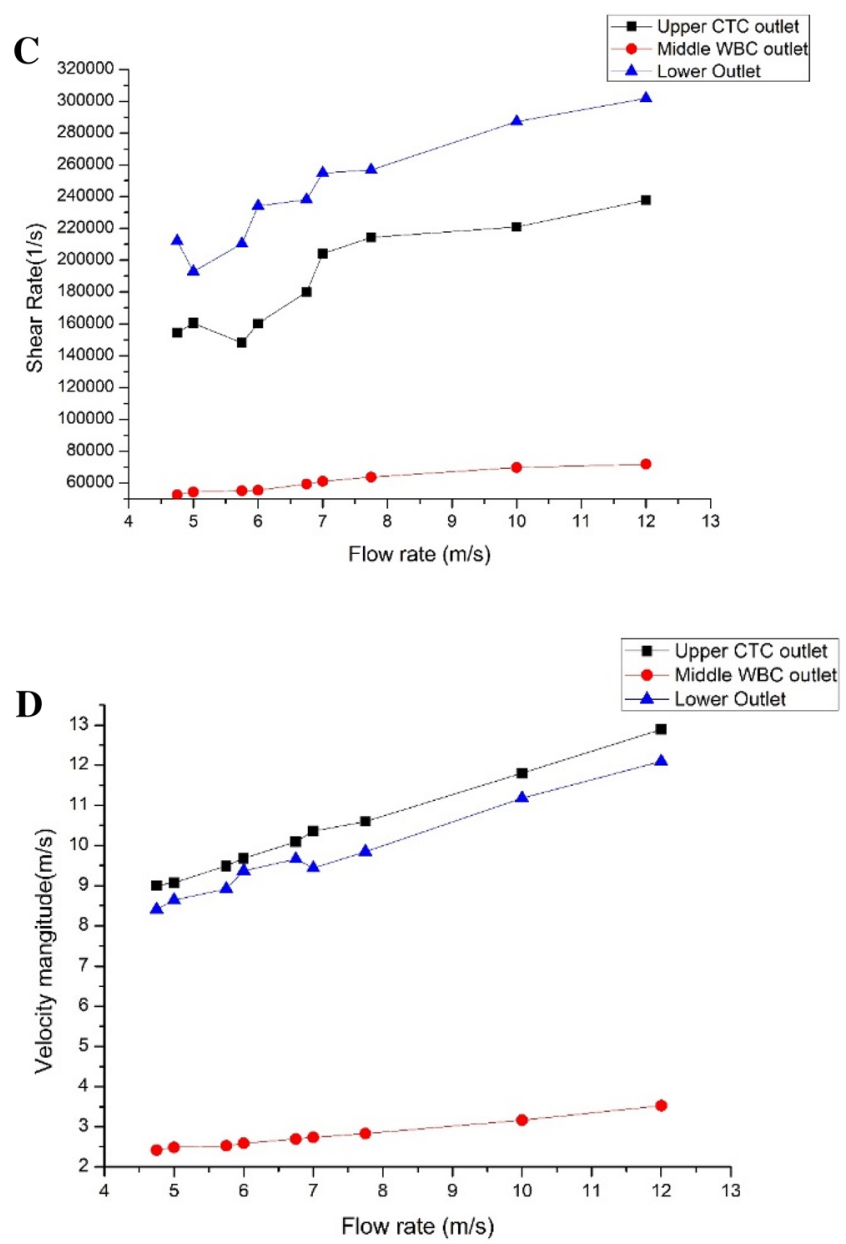

changes in sample flow rate $(\mathrm{m} / \mathrm{s})$ when water was used as conducting fluid. d Plot of variation of velocity magnitude $(\mathrm{m} / \mathrm{s})$ at different outlets with changes in sample flow rate $(\mathrm{m} / \mathrm{s})$ when water was used as conducting fluid 

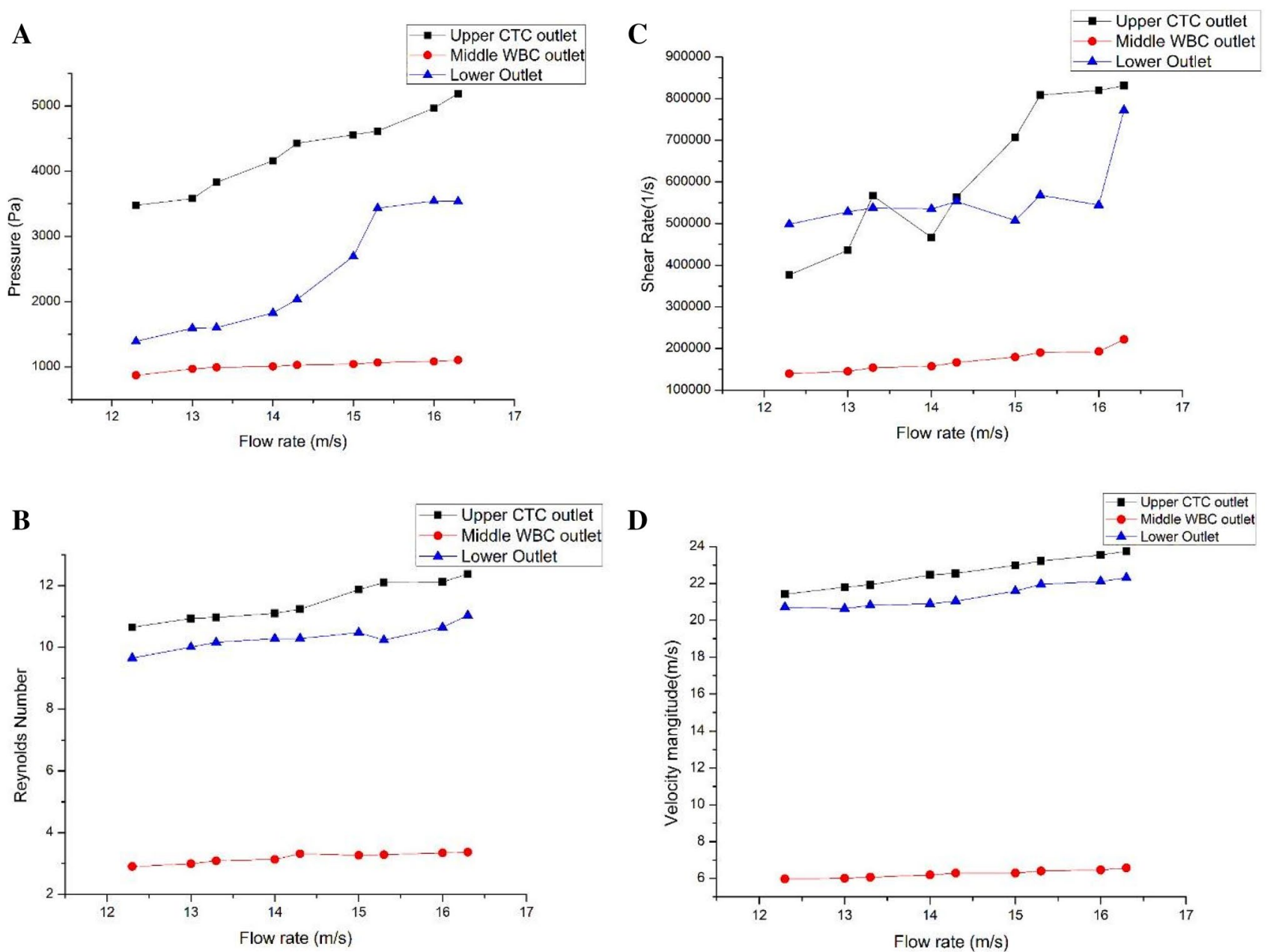

D

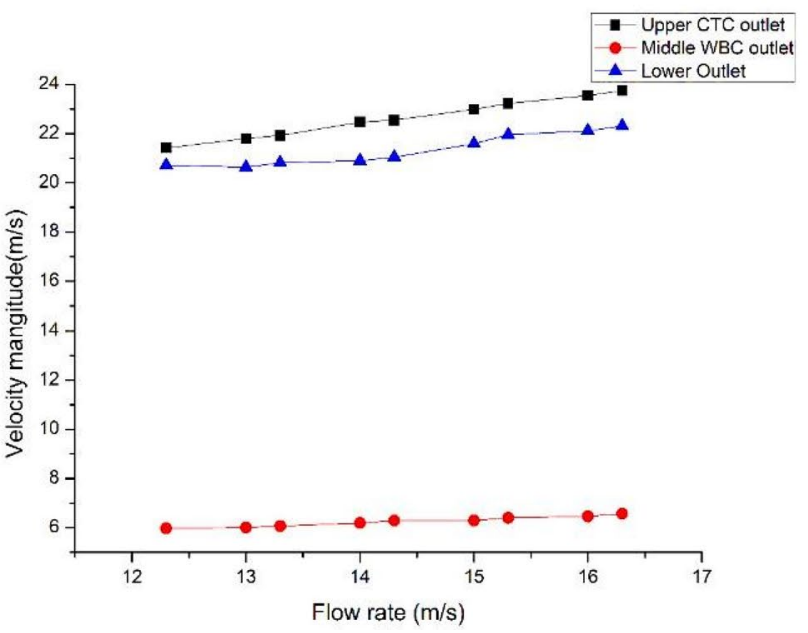

Fig. 9 a Plot of variation of pressure $(\mathrm{Pa})$ at different outlets with changes in sample flow rate $(\mathrm{m} / \mathrm{s})$ when water was used as conducting fluid. b Plot of variation of Reynolds number at different outlets with changes in sample flow rate $(\mathrm{m} / \mathrm{s})$ when blood was used as conducting fluid. c Plot of variation of shear rate $(1 / \mathrm{s})$ at different outlets with

changes in sample flow rate $(\mathrm{m} / \mathrm{s})$ when blood was used as conducting fluid. d Plot of variation of velocity magnitude $(\mathrm{m} / \mathrm{s})$ at different outlets with changes in sample flow rate $(\mathrm{m} / \mathrm{s})$ when blood was used as conducting fluid

Figure $8 \mathrm{c}$ showcases the variation of shear rate $(1 / \mathrm{s})$ at the three outlets with the changes in sample flow rate $(\mathrm{m} / \mathrm{s})$. The plot clearly highlights the uniformity in shear rate (1/s) at different outlets after the separation point of CTCs, i.e., at $4.5 \mathrm{~m} / \mathrm{s}$ with water as the conducting fluid.

Figure $8 \mathrm{~d}$ showcases the variation of velocity magnitude $(\mathrm{m} / \mathrm{s})$ at the three outlets with the changes in sample flow rate $(\mathrm{m} / \mathrm{s})$. The plot clearly shows the uniformity in velocity magnitude $(\mathrm{m} / \mathrm{s})$ at different outlets after the separation point of CTCs, i.e., at $4.5 \mathrm{~m} / \mathrm{s}$ with water as the conducting fluid.

\subsubsection{Plot of variation of flow parameters with changes in sample velocity flow rate with blood as the conducting fluid}

Figure 9a showcases the variation of pressure $(\mathrm{Pa})$ at the three outlets with the changes in sample flow rate $(\mathrm{m} / \mathrm{s})$. The plot clearly highlights the uniformity in pressure distribution at different outlets after the separation point of CTCs, i.e., at $12.3 \mathrm{~m} / \mathrm{s}$ with blood as the conducting fluid. 
Figure $9 \mathrm{~b}$ showcases the variation of Reynolds number at the three outlets with the changes in sample flow rate $(\mathrm{m} / \mathrm{s})$. The plot clearly highlights the uniformity in Reynolds number at different outlets after the separation point of CTCs, i.e., at $12.3 \mathrm{~m} / \mathrm{s}$ with blood as the conducting fluid.

Figure $9 \mathrm{c}$ showcases the variation of shear rate $(1 / \mathrm{s})$ at the three outlets with the changes in sample flow rate $(\mathrm{m} / \mathrm{s})$. The plot clearly highlights the uniformity in shear rate $(1 / \mathrm{s})$ at different outlets after the separation point of CTCs, i.e., at $12.3 \mathrm{~m} / \mathrm{s}$ with blood as the conducting fluid.

Figure 9d showcases the variation of Velocity magnitude $(\mathrm{m} / \mathrm{s})$ at the three outlets with the changes in sample flow rate $(\mathrm{m} / \mathrm{s})$. The plot clearly highlights the uniformity in velocity magnitude $(\mathrm{m} / \mathrm{s})$ at different outlets after the separation point of CTCs, i.e., at $12.3 \mathrm{~m} / \mathrm{s}$ with blood as the conducting fluid.

\section{Plot of separation ratio of particles through outlets with changes in sample flow rate}

An approximate value of separation ratio in percentage was estimated based on the trajectory of particles passing through the respective outlets and corresponding results are displayed in Tables 3 and 4 and the plot showing variation of separation ratio with respect to velocity flow rate and mass flow rate are shown in Figs. 10 and 11, respectively. The plot clearly highlights that maximum separation ratio is observed at a sample velocity flow rate of $12.3 \mathrm{~m} / \mathrm{s}$ and

Table 3 Approximate separation ratio (\%) of cells through respective outlets for different velocity flow rates

\begin{tabular}{lll}
\hline $\begin{array}{l}\text { Sample velocity } \\
\text { flow rate (m/s) with } \\
\text { blood as conducting } \\
\text { medium }\end{array}$ & $\begin{array}{l}\text { Separation ratio (\%) } \\
\text { of CTCs through } \\
\text { upper CTC Outlet } \\
\text { (Appx.) }\end{array}$ & $\begin{array}{l}\text { Separation ratio (\%) of } \\
\text { WBCs through middle } \\
\text { WBC Outlet (Appx.) }\end{array}$ \\
\hline 11 & 69 & 64 \\
11.3 & 71 & 62 \\
12 & 83 & 79 \\
12.3 & 87.5 & 95 \\
13 & 67.5 & 70 \\
13.3 & 65 & 65 \\
\hline
\end{tabular}

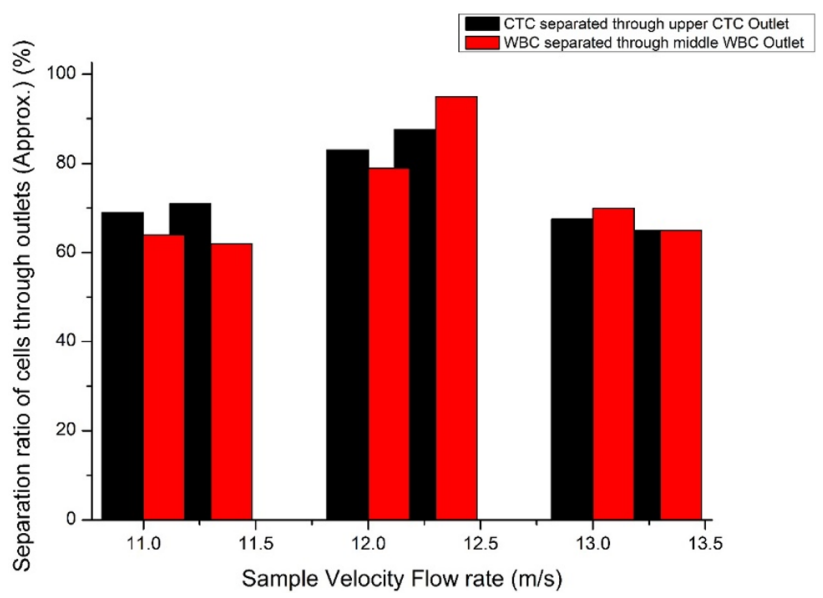

Fig. 10 Plot showing variation of approximate separation ratio of CTCs and WBCs with respect to different sample velocity flow rates

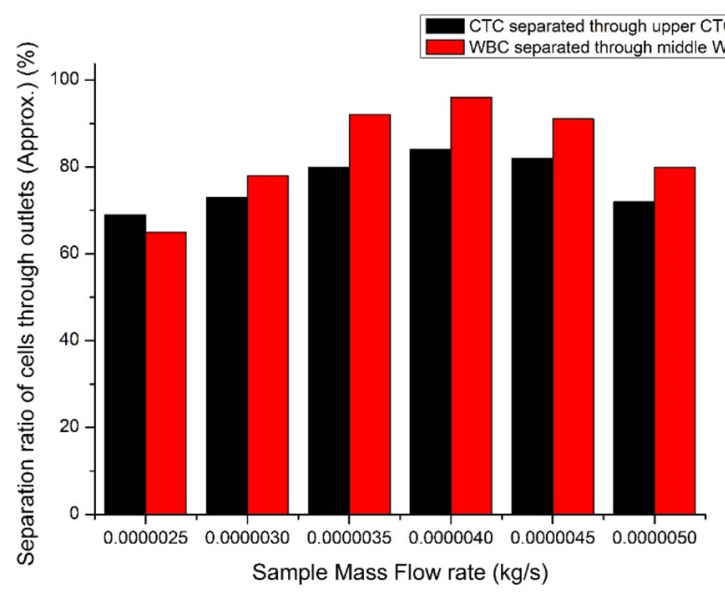

Fig. 11 Plot showing variation of approximate separation ratio of CTCs and WBCs with respect to different sample mass flow rates

sample mass flow rate of $4 \times 10^{-6} \mathrm{~kg} / \mathrm{s}$ with blood as the conducting medium.

Figure 10 clearly indicates the variation of approximate separation ratio of CTCs and WBCs through upper CTC
Table 4 Approximate separation ratio (\%) of cells through respective outlets for different mass flow rates

\begin{tabular}{lll}
\hline $\begin{array}{l}\text { Sample mass flow rate } \\
(\mathrm{kg} / \mathrm{s})\end{array}$ & $\begin{array}{l}\text { Separation ratio (\%) of CTCs through } \\
\text { upper CTC outlet (Appx.) }\end{array}$ & $\begin{array}{l}\text { Separation ratio (\%) of WBCs } \\
\text { through middle WBC outlet } \\
\text { (Appx.) }\end{array}$ \\
\hline $2.5 \times 10^{-6}$ & 69 & 65 \\
$3 \times 10^{-6}$ & 73 & 78 \\
$3.5 \times 10^{-6}$ & 80 & 92 \\
$4 \times 10^{-6}$ & 84 & 96 \\
$4.5 \times 10^{-6}$ & 82 & 91 \\
$5 \times 10^{-6}$ & 72 & 80 \\
\hline
\end{tabular}


outlet and middle WBC outlet, respectively, with changes in sample velocity flow rate $(\mathrm{m} / \mathrm{s})$. The maximum separation ratio for CTCs and WBCs was obtained as $87.5 \%$ and $95 \%$, respectively, at sample flow rate of $12.3 \mathrm{~m} / \mathrm{s}$ with blood acting as the conducting fluid.

Figure 11 clearly indicates the variation of approximate separation ratio of CTCs and WBCs through upper CTC outlet and middle WBC outlet, respectively, with changes in sample mass flow rate $(\mathrm{kg} / \mathrm{s})$. The maximum separation ratio for CTCs and WBCs were obtained as $84 \%$ and $96 \%$, respectively, at sample mass flow rate of $4 \times 10^{-6} \mathrm{~kg} / \mathrm{s}$ with blood acting as the conducting fluid.

\section{Conclusion}

The research study on designing an efficient microchannel for isolation of CTCs from WBCs explores the effectiveness of DLD in sorting of blood cells. We have successfully proposed and analyzed an optimized microfluidic channel based on DLD technique to separate the CTCs from WBCs in an injected blood sample both theoretically and through simulations using COMSOL Multiphysics 5.4 software. The proposed model of the microchannel operates successfully for effective separation at both lower mass flow rates and higher mass flow rates, tested at $4 \times 10^{-6} \mathrm{~kg} / \mathrm{s}$ showing appreciable separation ratio of $87.5 \%$ and $84 \%$, respectively, at $12.5 \mathrm{~m} / \mathrm{s}$ velocity flow rate and $4 \times 10^{-6}$ mass flow rate, especially for high-throughput operations. The microchannel was also tested with velocity flow rate and was found to effectively separate CTCs at high sample flow rate of $12.5 \mathrm{~m} / \mathrm{s}$. Furthermore, the model offers excellent linearity in terms of pressure, velocity magnitude, shear rate and Reynolds number with the variation of velocity flow rate. Additionally, the presence of three symmetrically aligned outlets lead to symmetric distribution of fluid pressure thereby reducing chances of clogging. Thus, the proposed microchannel design is better suited for isolation of CTCs from WBCs with higher separation efficiency, offering better throughput and linearity of flow parameters and limiting clogging issues to a greater extent when compared with existing designs.

Open Access This article is licensed under a Creative Commons Attribution 4.0 International License, which permits use, sharing, adaptation, distribution and reproduction in any medium or format, as long as you give appropriate credit to the original author(s) and the source, provide a link to the Creative Commons licence, and indicate if changes were made. The images or other third party material in this article are included in the article's Creative Commons licence, unless indicated otherwise in a credit line to the material. If material is not included in the article's Creative Commons licence and your intended use is not permitted by statutory regulation or exceeds the permitted use, you will need to obtain permission directly from the copyright holder. To view a copy of this licence, visit http://creativecommons.org/licenses/by/4.0/.

\section{References}

1. Li W, Tsou C (2015) Study of different cross-shaped microchannels affecting thermal-bubble-actuated microparticle manipulation. SPIE J Micro/Nanolithogr MEMS MOEMS 14(4):045001

2. Schertzer MJ, Mrad RB, Sullivan PE (2012) Automated detection of particle concentration and chemical reactions in EWOD devices. Sens Actuators B 164(1):1-6

3. Neethirajan S, Kobayashi I, Nakajima M, Dan Wu, Nandagopal S, Lin F (2011) Microfluidic for food, agriculture and biosystems industries. Lab Chip 11:1574-1586

4. Manz A, Graber N, Widmer HM (1990) Miniaturized total chemical analysis systems: a novel concept for chemical sensing. Sens Actuators B 1(1-6):244-248

5. Sheron PF, Sridhar KP, Baskar S, Shakeel PM (2019) A decentralized scalable security framework for end to end authentication of future IoT communication. In: Transactions on emerging telecommunications technologies, p e 3815

6. Lin YY, Evans RD, Welch E, Hsu BN, Madison AC (2010) RB fair "low voltage electrowetting-on-dieletric platform using multi-layer insulators". Sens Actuators B 150(1):465-470

7. Luan L, Evans RD, Jokerst NM, Fair RB (2008) Integrated optical sensor in a digital microfluidics platform. IEEE Sens J 8(5):628-635

8. Washizu M (1998) Electrostatic actuation of liquid droplets for micro-reactor applications. IEEE Trans Ind Appl 34(4):732-737

9. Jensen MP, Ashley N, Koprowska K, Mir KU, Zalkovskij M, Bilenberg B, Marie R (2015) Separation of cancer cells from white blood cells by pinched flow fractionation. Lab Chip 15(24):4598-4606

10. Shakeel PM, Desa MI, Burhanuddin MA (2019) Improved watershed histogram thresholding with probabilistic neural networks for lung cancer diagnosis for CBMIR systems. In: Multimedia tools and applications, pp 1-19

11. Wang J, Lu W, Tang C, Liu Y, Sun J, Mu X, Zhang L, Dai B, Li X, Zhuo H, Jiang X (2015) Label-free isolation and mRNA detection of circulating tumor cells from patients with metastatic lung cancer for disease diagnosis and monitoring therapeutic efficacy. Anal Chem 87(23):11893-11900

12. Becker FF, Wang X-B, Huang Y, Pethig R, Vykoukal J, Gascoyne $P$ (1995) Separation of human breast cancer cells from blood by differential dielectric affinity. Proc Natl Acad Sci USA 92(3):860-864

13. Gascoyne PR, Wang XB, Huang Y, Becker FF (1997) Dielectrophoretic separation of cancer cells from blood. IEEE Trans Ind Appl 33(3):670-678

14. Zhang X, Hashem MA, Chen X, Tan H (2018) On passing a non-Newtonian circulating tumor cell (CTC) through a deformation-based microfluidic chip. Theor Comput Fluid Dyn 32(6):753-764

15. Fachin F, Spuhler P, Martel-Foley JM et al (2017) Monolithic chip for high-throughput blood cell depletion to sort rare circulating tumor cells. Sci Rep 7:10936

16. Chang C-L, Huang W, Jalal SI, Chan B-D, Mahmood A, Shahda S, O'Neil BH, Matei DE, Savran CA (2015) Circulating tumor cell detection using a parallel flow micro-aperture chip system. Lab Chip 15:1677-1688

17. Fan X, Jia C, Yang J, Li G, Mao H, Jin Q, Zhao J (2015) A microfluidic chip integrated with a high-density PDMS-based microfiltration membrane for rapid isolation and detection of circulating tumor cells. Biosens Bioelectron 71:380-386

18. Nathamgari SSP, Dong B, Zhou F, Kang W, Giraldo- Vela JP, McGuire T, McNaughton RL, Sun C, Kessler JA, Espinosa HD (2015) Isolating single cells in a neurosphere assay using inertial microfluidics. Lab Chip 15:4591-4597 
19. Liu Z, Huang F, Du J, Shu W, Feng H, Xu X, Chen Y (2013) Rapid isolation of cancer cells using microfluidic deterministic lateral displacement structure. Biomicrofluidics 7:011801

20. Chen Y, Wu M, Ren L, Liu J, Whitley PH, Wang L, Huang TJ (2016) High-throughput acoustic separation of platelets from whole blood. Lab Chip 16:3466-3472

21. Cheng IF, Huang W-L, Chen T-Y, Liu C-W, Lin Y-D, Su W-C (2015) Antibody-free isolation of rare cancer cells from blood based on 3D lateral dielectrophoresis. Lab Chip 15:2950-2959

22. McGrath J, Jimenez M, Bridle H (2014) Deterministic lateral displacement for particle separation: a review. Lab Chip $14: 4139-4158$

23. Kottmeier J, Weber MW, Blahout S, Hussong J, Kampen I, Kwade A, Dietzel A (2019) Accelerated particle separation in a DLD device at Re $>1$ investigated by means of $\mu$ PIV. Micromachines 10:768
24. Aghilinejad A, Aghaamoo M, Chen X (2019) On the transport of particles/cells in high-throughput deterministic lateral displacement devices: implications for circulating tumor cell separation. Biomicrofluidics 13:034112

25. Zhou J, Kulasinghe A, Bogseth A et al (2019) Isolation of circulating tumor cells in non-small-cell-lung-cancer patients using a multi-flow microfluidic channel. Microsyst Nanoeng 5(8):1-12

26. Phillips KG et al (2012) Optical quantification of cellular mass, volume, and density of circulating tumor cells identified in an ovarian cancer patient. Front Oncol 2:72

Publisher's Note Springer Nature remains neutral with regard to jurisdictional claims in published maps and institutional affiliations. 